\title{
'What would you do if you were me, doctor?': randomised trial of psychiatrists' personal v. professional perspectives on treatment recommendations ${ }^{\dagger}$
}

Rosmarie Mendel, Johannes Hamann, Eva Traut-Mattausch, Markus Bühner, Werner Kissling and Dieter Frey

\section{Background}

If patients are unsure whether a specific treatment is really good for them, they often pose the question, 'What would you do if you were me, doctor?' Patients want their psychiatrists to put themselves in their shoes and not to give a 'standard recommendation'.

\section{Aims \\ To study whether this question really leads psychiatrists to reveal their personal preferences.}

\section{Method}

Randomised experimental study with 515 psychiatrists incorporating two decision scenarios (depression scenario: antidepressant $v$. watchful waiting; schizophrenia scenario: depot $v$. oral antipsychotic) and three experimental conditions (giving a recommendation to a patient asking, 'What would you do if you were me, doctor?'; giving a regular recommendation to a patient without being asked this question; and imagining being ill and deciding for yourself). Main outcome measures were the treatments chosen or recommended by physicians.

\section{Results}

Psychiatrists choosing treatment for themselves predominantly selected other treatments (mostly watchful waiting and oral antipsychotics respectively) than what psychiatrists recommended to patients when asked in the 'regular recommendation role' (i.e. antidepressant and depot respectively). Psychiatrists in the 'what-would-you-do role' gave recommendations similar to the 'regular recommendation role' (depression scenario: $\chi^{2}=0.12$, $P=0.73$; schizophrenia scenario: $\chi^{2}=2.60, P=0.11$ ) but distinctly different from the 'self role'.

\section{Conclusions}

The question 'What would you do if you were me, doctor?' does not motivate psychiatrists to leave their professional recommendation role and to take a more personal perspective. Psychiatrists should try to find out why individuals are asking this question and, together with the individual, identify the most appropriate treatment option.

\section{Declaration of interest}

R.M. has received honoraria from Janssen-Cilag. J.H. has received honoraria and/or research supports from Boehringer, Eli Lilly, Janssen-Cilag, Sanofi-Aventis, Astra Zeneca and Bristol-Myers Squibb. W.K. has received honoraria and/or research supports from Janssen-Cilag, Sanofi-Aventis, Johnson \& Johnson, Pfizer, Bristol-Myers Squibb, AstraZeneca, Lundbeck, Novartis and Eli Lilly.
'What would you do if you were me, doctor?' is a question that is often posed to doctors when individuals have a decisional conflict and when they are unsure which treatment to choose. ${ }^{1}$ By asking this question, patients expect doctors to go beyond giving professional advice and reveal their personal preferences by imagining themselves in the patient's situation. ${ }^{2}$ Many patients believe that doctors, when deciding for themselves, would choose the best option ${ }^{3}$ since they are free from strategic considerations (for example financial limitations, physicians' self-interests). And in fact, there is evidence that the treatment doctors choose for themselves sometimes differs from the treatment they recommend to their patients. ${ }^{4,5}$ Doctors, for example, are less likely to have surgery than the general population, and although they might recommend taking part in clinical trials to their patients, they are less inclined to do so themselves. ${ }^{6,7}$ In psychiatry, it has also been shown that some health professionals reject the same therapies for themselves that are typically prescribed to patients. ${ }^{8}$ Many individuals with psychiatric conditions are sceptical about psychotropic drugs and the evidence is often ambiguous as to what benefit can really be expected from medications (for example

†See editorial, pp. 429-430, this issue. antidepressants). ${ }^{9}$ In these cases such patients might be especially interested in what their psychiatrists would choose for themselves. However, despite patients often asking 'What would you do if you were me, doctor?' little is known about how psychiatrists react to this question and whether they truly recommend what they would choose for themselves if they were ill.

\section{Method}

\section{Design}

We chose a randomised experimental design with two different decision scenarios: the first treatment for an individual with depression and the second treatment for an individual with schizophrenia; both were described in a case vignette. The study included three experimental conditions: psychiatrists were told to imagine that they were the treating physician and had to give a regular recommendation to the individual ('regular recommendation role'); psychiatrists were told to imagine that they were ill and had to decide for themselves ('self role'); psychiatrists were told to imagine that they were the treating physician being asked 'What would you do if you were me, doctor' by the individual ('what-would-you-do role'). 
In each scenario, participating psychiatrists could choose between two treatment options (depression scenario: watchful waiting $v$. antidepressant; schizophrenia scenario: oral $v$. depot antipsychotic). The decisions between watchful waiting and antidepressant and between oral antipsychotic and depot antipsychotic were chosen because both are frequent in the daily routine and evidence does not suggest that one option is clearly superior to the other. Therefore we expected to see a difference between the self role and the regular recommendation role.

As in studies with lay people, we imagined that physicians in the self role would more often choose the less invasive treatment options (watchful waiting and oral medication) than in the regular recommendation role. ${ }^{10,11}$ Two different decision scenarios (depression scenario and schizophrenia scenario) were used to learn whether physicians' behaviour is also affected by the type of decision scenario, not just by their role. Study participants were asked to participate in a 'medical decision-making' questionnaire. In order to avoid influencing the participants' responses, no specific information was given about the study. The study was approved by the institutional review board (Ethikkommission der Technischen Universität München).

\section{Participants}

Participants were 515 psychiatrists recruited consecutively during the annual congress of the German Psychiatric Association (Deutsche Gesellschaft für Psychiatrie, Psychotherapie und Nervenheilkunde), Germany. All attending psychiatrists were eligible. The response rate was almost $90 \%$.

\section{Procedure}

Questionnaires were sorted in a randomised manner and then consecutively handed out to participants. Participating psychiatrists received a questionnaire containing one of the two scenarios (depression or schizophrenia) and one of the three experimental conditions (recommendation role, what-wouldyou-do role or self role). After reading the case vignette, the participants were requested to make a choice between two treatment options (Fig. 1 and Appendix).

\section{Depression scenario}

In this scenario, psychiatrists in the recommendation role and in the what-would-you-do role were asked to imagine treating an out-patient with depressive symptoms. Psychiatrists in the self role were asked to imagine that they had depressive symptoms themselves and were being treated by a psychiatrist as an out-patient. The two treatment options to choose from were immediate treatment with an antidepressant and watchful waiting. In the regular recommendation role and the what-would-you-do role, psychiatrists were asked to indicate what kind of treatment they would recommend to the patient. In the self role, the psychiatrists were requested to decide what treatment option they would prefer if they had depression themselves. Depressive symptoms presented in the case vignettes were identical in all three conditions.

\section{Schizophrenia scenario}

The structure of this scenario was identical to the depression scenario. Psychiatrists were asked to imagine treating an

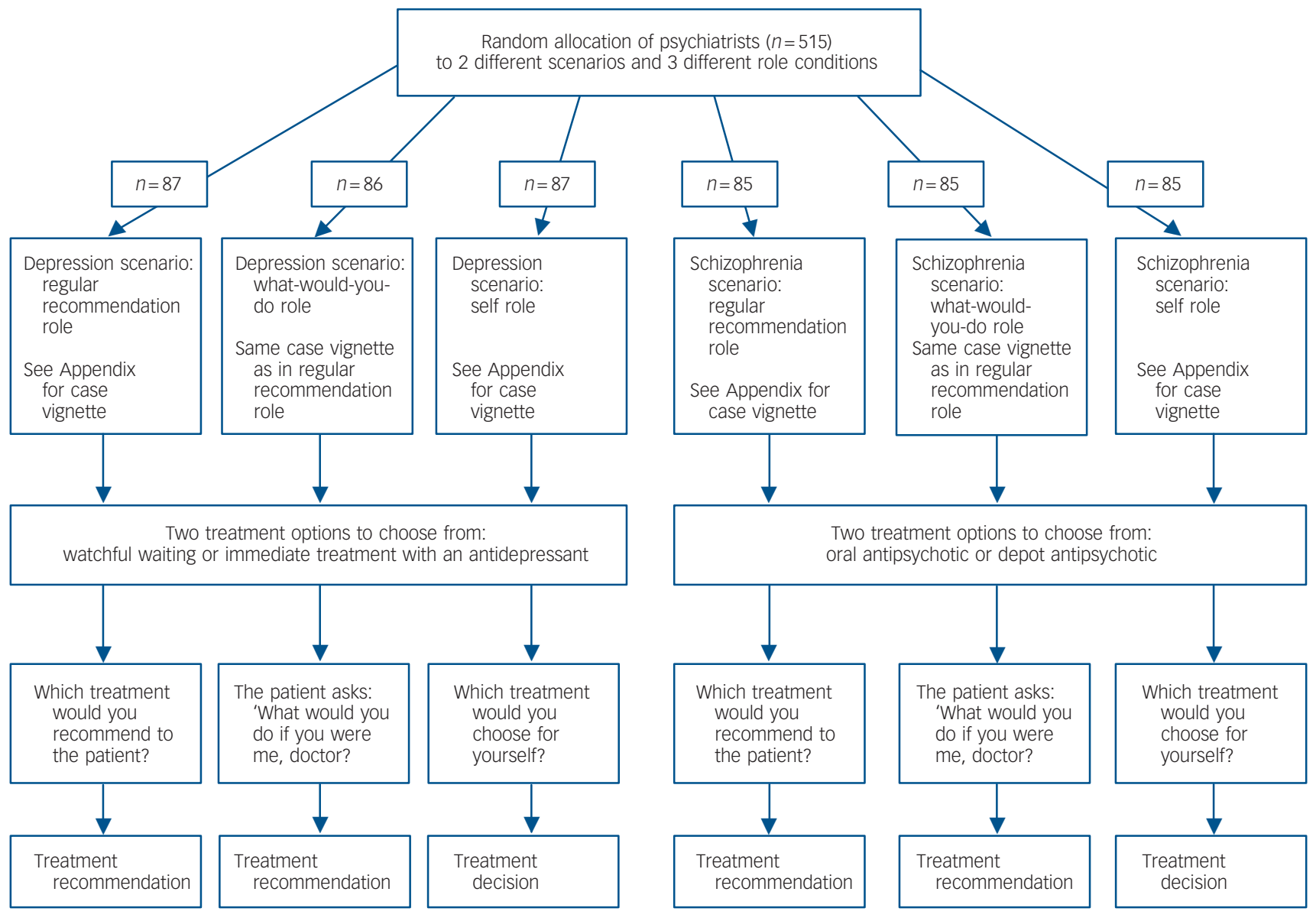

Fig. 1 Procedure. 
out-patient experiencing a second relapse of schizophrenia (in the self role: to imagine having the disease themselves). It was additionally mentioned that the patient (in the self role: the physician) sometimes forgets to take the antipsychotic medication. The two treatment options to choose from were treatment with an oral antipsychotic or a depot antipsychotic.

After making the treatment decision for their assigned scenario, psychiatrists answered additional questions about their opinion of the effectiveness of the treatment options, about the importance of whether the treatment choice is in accordance with treatment guidelines and about the unpleasantness of the treatment options for the patient/for themselves (6-point Likert scale ranging from 'low' (1) to 'high' (6)). All participants were requested to supply their age, gender and professional psychiatric experience, along with the percentage of their patients with depression (depression scenario) or schizophrenia (schizophrenia scenario). All responses were anonymous.

\section{Data analysis}

To test whether treatment selections differed across the three conditions (regular recommendation role, what-would-you-do role and self role) we used chi-squared tests, including post hoc comparisons. Analyses of variance (also including post hoc Scheffé comparisons) were used to investigate whether psychiatrists in different roles also vary with respect to different aspects of treatment choice (for example perceived effectiveness of treatment options, importance that treatment choice is in accordance with treatment guidelines). Additionally, paired $t$-tests were applied for within-group comparisons. A hierarchical logistic regression analysis was conducted to test whether the role had, independently of several factors (variables tested in the above mentioned analyses of variance and sociodemographic variables), influenced the psychiatrists' treatment selection. We used a hierarchical approach because we wanted to explore, first of all, the effect of the role and second, the effect of other variables included in the regression analysis. A two-sided $P<0.05$ was considered significant. Data were analysed using the SPSS Version 16.0 for Windows.

\section{Results}

We asked 578 psychiatrists to fill out the questionnaire. In total $7 \%$ of them $(n=40)$ refused to take part in the study, another

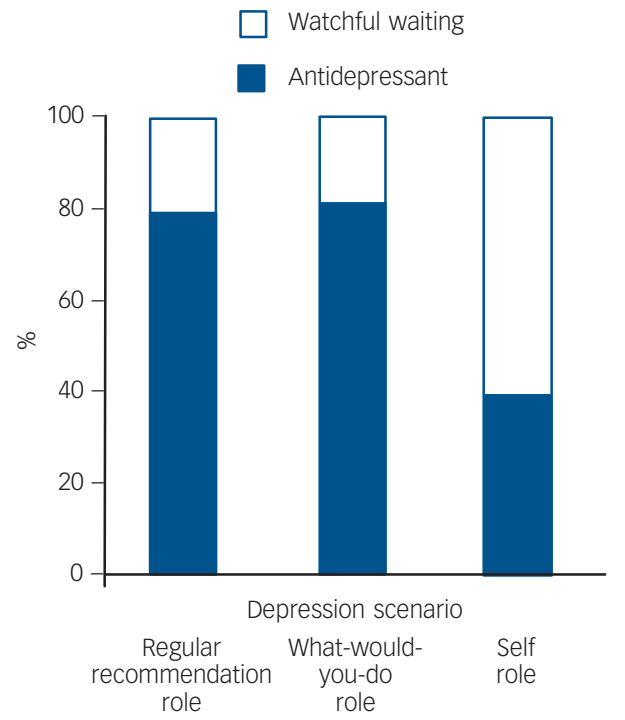

$4 \%(n=23)$ did not return the questionnaire, giving an overall response rate of $89 \%$. Thus, a total of 515 psychiatrists (228 females, 285 males; data missing for 2) took part in the study. Their mean age was 46.1 years $($ s.d. $=9.4)$ and their professional experience averaged 15.0 years (s.d.=9.7). About $67.2 \%$ of the psychiatrists worked in a psychiatric hospital and 30.5\% worked in private practice; $2.3 \%$ of the participants worked in neither a hospital nor a private practice. Differences regarding sociodemographic variables were not found between the two different decision scenarios or between the three different role conditions.

\section{Influence of psychiatrists' role on treatment decisions}

The results of both scenarios showed that psychiatrists preferred different treatment options depending on their role in the decision process (depression scenario: $\chi^{2}=44.36, P<0.001$; schizophrenia scenario: $\left.\chi^{2}=37.79, P<0.001\right)$. Post hoc comparisons revealed that psychiatrists in both scenarios of the what-would-you-do role differed significantly from psychiatrists in the self role (depression scenario: $\chi^{2}=32.30, P<0.001$; schizophrenia scenario: $\chi^{2}=36.66$, $P<0.001)$ but not from psychiatrists in the regular recommendation role (depression scenario: $\chi^{2}=0.12, P=0.73$; schizophrenia scenario: $\left.\chi^{2}=2.60, P=0.11\right)$. Moreover, differences between psychiatrists in the regular recommendation role and psychiatrists in the self role were also significant (depression scenario: $\chi^{2}=29.15$, $P<0.001$; schizophrenia scenario: $\left.\chi^{2}=20.93, P<0.001\right)$.

With regard to treatment options, psychiatrists in the whatwould-you-do role and in the regular recommendation role more often chose an antidepressant in the depression scenario and a depot medication in the schizophrenia scenario than psychiatrists in the self role (psychiatrists who chose an antidepressant: what-would-you-do role $81.4 \%$, regular recommendation role $79.3 \%$, self role $39.1 \%$; psychiatrists who chose a depot medication: what-would-you-do role $58.8 \%$, regular recommendation role $46.4 \%$, self role $14.1 \%$; Fig. 2).

Taken together, these findings indicate that psychiatrists chose distinctly different therapies when deciding in the self role compared with the regular recommendation role and the question 'What would you do if you were me, doctor?' apparently did not motivate psychiatrists to reveal their true personal preferences.

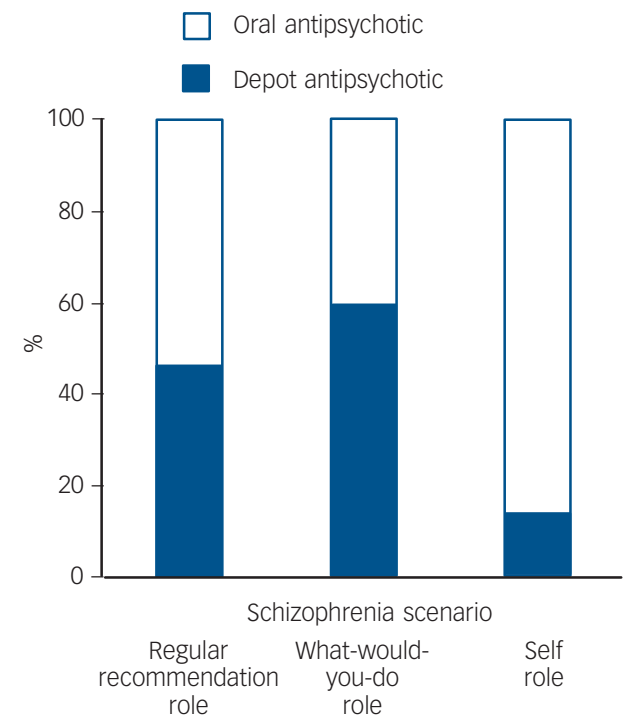

Fig. 2 Chosen treatment options in relation to psychiatrists' role. 


\section{Influence of psychiatrists' role on attitudes towards treatment options}

In accordance with the differences seen in treatment choices, psychiatrists' rating of additional treatment aspects was also dependent on the role they were asked to imagine themselves in. For both scenarios, psychiatrists in the what-would-you-do role behaved differently from psychiatrists in the self role, but similarly to the psychiatrists in the regular recommendation role (Table 1). Thus, psychiatrists in the what-would-you-do role and in the regular recommendation role recommended treatment options that were in accordance with treatment guidelines more than psychiatrists in the self role. In addition, they perceived the more invasive option (antidepressants in the depression scenario and depot medication in the schizophrenia scenario) as less unpleasant for the patient than psychiatrists in the self role perceived it for themselves.

There were no differences between the roles regarding the perceived effectiveness of the more invasive treatments (antidepressants in the depression scenario and depot medication in the schizophrenia scenario). The less invasive options (watchful waiting in the depression scenario and oral medication in the schizophrenia scenario), however, were considered by psychiatrists in the self role to be more effective than by psychiatrists in the two other roles.

Paired $t$-tests revealed that in all three role conditions the more invasive options of antidepressant and depot medication were estimated to be more effective than the non-invasive options of watchful waiting and oral medication (depression scenario: what-would-you-do role: $t=10.46, P<0.001$; regular recommendation role: $t=10.21, P<0.001$; self role: $t=5.53, P<0.001$; schizophrenia scenario: what-would-you-do role: $t=7.20$, $P<0.001$; regular recommendation role: $t=6.39, P<0.001$; self role: $t=2.33, P=0.02$ ).

\section{Hierarchical logistic regression analysis to control for confounding factors}

We performed a hierarchical logistic regression to test whether the role of the psychiatrists had, independently of the abovementioned factors (for example importance of guidelines), influenced the choice of treatment. Additionally, we controlled for sociodemographic variables. In bloc 1 the independent variable was 'role. In bloc 2 the additional factors and sociodemographic variables were entered (Table 2). In bloc 1, we found a strong effect for role (depression scenario: $R^{2}=0.19$; schizophrenia scenario: $\left.R^{2}=0.20\right)$ : psychiatrists in the self role more often chose the less invasive treatment option than psychiatrists in the what-would-you-do role (depression scenario: odds ratio $(\mathrm{OR})=5.96(95 \%$ CI $2.95-12.06), P<0.001$; schizophrenia scenario: $\mathrm{OR}=8.43(95 \%$ CI 3.96-17.96), $P<0.001)$. However, psychiatrists in the regular recommendation role did not differ from psychiatrists in the what-would-you-do role (depression scenario: $\mathrm{OR}=1.06$ (95\% CI $0.50-2.28), P=0.88$; schizophrenia scenario: $\mathrm{OR}=1.71(95 \%$ CI $0.91-3.22), P=0.10)$. Bloc 2 (depression scenario: $R^{2}=0.52$; schizophrenia scenario: $\left.R^{2}=0.66\right)$ showed that the incremental effect of the additional variables entered in this bloc was also strong. In addition to role, other predictors, such as 'unpleasantness of the invasive treatment option for the patient', influenced the kind of treatment chosen/ recommended.

\section{Discussion}

Our survey revealed two major findings. First, psychiatrists choosing a treatment for themselves predominantly selected a

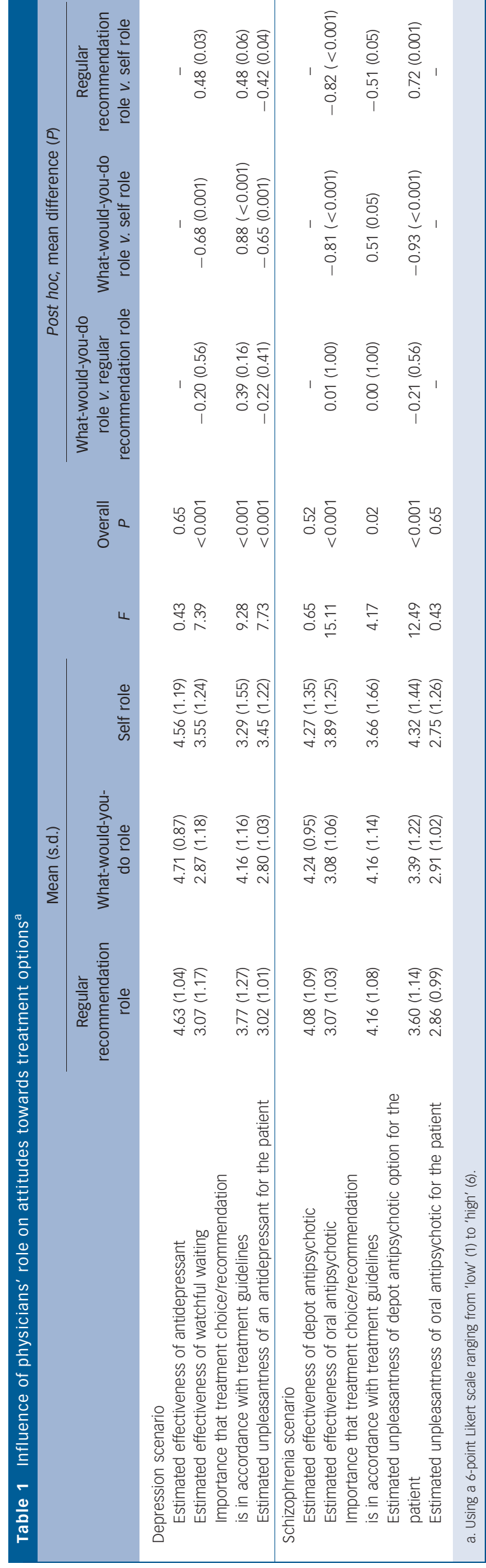


Table 2 Logistic regression models for choosing the less invasive treatment options (watchful waiting in the depression scenario and oral antipsychotic in the schizophrenia scenario)

\begin{tabular}{|c|c|c|c|c|c|c|}
\hline & \multicolumn{3}{|c|}{ Depression scenario $^{a}$} & \multicolumn{3}{|c|}{ Schizophrenia scenario ${ }^{\mathrm{b}}$} \\
\hline & OR $(95 \% \mathrm{Cl})$ & $P$ & $R^{2}$ & OR $(95 \% \mathrm{Cl})$ & $P$ & $R^{2}$ \\
\hline $\begin{array}{l}\text { Bloc } 1 \\
\text { Experimental condition }\end{array}$ & & & 0.19 & & & 0.20 \\
\hline What-would-you-do role & Reference & & & Reference & & \\
\hline Regular recommendation role & $1.06(0.50-2.28)$ & 0.88 & & $1.71(0.91-3.22)$ & 0.10 & \\
\hline Self role & $5.96(2.95-12.06)$ & $<0.001$ & & $8.43(3.96-17.96)$ & $<0.001$ & \\
\hline Bloc 2 & & & 0.52 & & & 0.66 \\
\hline Experimental condition & & & & & & \\
\hline What-would-you-do role & Reference & & & Reference & & \\
\hline Regular recommendation role & $1.03(0.41-2.56)$ & 0.96 & & $1.66(0.69-4.00)$ & 0.26 & \\
\hline Self role & $5.01(2.03-12.41)$ & $<0.001$ & & $11.66(3.52-38.63)$ & $<0.001$ & \\
\hline Estimated effectiveness of invasive treatment option ${ }^{c}$ & $0.65(0.46-0.91)$ & 0.01 & & $0.58(0.38-0.89)$ & 0.01 & \\
\hline Estimated effectiveness of non-invasive treatment option ${ }^{d}$ & $2.55(1.85-3.53)$ & $<0.001$ & & $3.21(2.01-5.12)$ & $<0.001$ & \\
\hline $\begin{array}{l}\text { Importance that treatment choice/recommendation is in } \\
\text { accordance with treatment guidelines }\end{array}$ & $1.05(0.81-1.37)$ & 0.71 & & $1.07(0.74-1.55)$ & 0.71 & \\
\hline Estimated unpleasantness of invasive treatment option ${ }^{d}$ & $1.64(1.18-2.27)$ & 0.003 & & $2.68(1.86-3.87)$ & $<0.001$ & \\
\hline Estimated unpleasantness of non-invasive treatment option ${ }^{d}$ & - & - & & $0.43(0.28-0.67)$ & $<0.001$ & \\
\hline \multicolumn{7}{|l|}{ Psychiatrists' gender } \\
\hline Female & Reference & & & Reference & & \\
\hline Male & $1.18(0.56-2.49)$ & 0.67 & & $2.29(0.98-5.35)$ & 0.06 & \\
\hline Psychiatrists' age & $0.96(0.87-1.05)$ & 0.34 & & $0.96(0.89-1.04)$ & 0.33 & \\
\hline \multicolumn{7}{|l|}{ Psychiatrists' place of work } \\
\hline Hospital & Reference & & & Reference & & \\
\hline Private practice & $0.41(0.16-1.08)$ & 0.07 & & $0.77(0.28-2.16)$ & 0.62 & \\
\hline Psychiatrists' professional experience & $1.01(0.93-1.11)$ & 0.76 & & $1.02(0.94-1.10)$ & 0.63 & \\
\hline \multirow{2}{*}{$\begin{array}{l}\text { Percentage of patients with depression (in schizophrenia scenario: } \\
\text { schizophrenia) actually treated by participating psychiatrist) }\end{array}$} & & & & & & \\
\hline & $0.99(0.97-1.01)$ & 0.46 & & $0.98(0.96-1.00)$ & 0.12 & \\
\hline $\begin{array}{l}\text { a. } 13 \text { responses were excluded because of missing data. } \\
\text { b. } 15 \text { responses were excluded because of missing data. } \\
\text { c. Invasive treatment option: antidepressant and depot antipsychotic. } \\
\text { d. Non-invasive treatment option: watchful waiting and oral antipsychotic. }\end{array}$ & & & & & & \\
\hline
\end{tabular}

different treatment than the one recommended to patients by participants asked in the regular recommendation role. Psychiatrists preferred the less effective, less invasive and more risky options for themselves (i.e. watchful waiting and oral antipsychotics) whereas they recommended the more effective and invasive ones for the patient (i.e. antidepressants and depot injections). Second, psychiatrists asked by a patient, 'what would you do if you were me, doctor?' remained in their usual professional recommendation role and usually did not recommend the same treatment options as those most often chosen by psychiatrists deciding in the self role.

\section{Why do psychiatrists choose different treatments for themselves than for their patients?}

First of all, psychiatrists may see themselves as better educated than most of their patients and thus more competent to take action when the less invasive but also less effective treatment (for example 'wait and see') has failed. Doctors might assume that their patients are not reliable enough to return for more intense treatment should a less effective/less invasive treatment fail.

Second, psychiatrists might hesitate to recommend the more risky option (for example 'wait and see') to the patient, because they might be held accountable for negative consequences (for example a suicide attempt) of this decision. In fact, evidence shows that accountability to others motivates advice givers to act differently than when making a personal decision. ${ }^{12}$

Third, personal decision makers have been reported to weigh dimensions of options differently than advice givers. ${ }^{13,14}$ Physicians in our study more often preferred the more effective but also more inconvenient treatment options (antidepressant and depot medication) for patients than for themselves. This may be explained by physicians in their usual recommendation role tending to focus predominantly on outcomes and benefits of medication whereas personal decision makers (psychiatrists in the self role) also consider inconvenience, cost and adverse effects when deciding to start or continue medications. ${ }^{15}$

Fourth, psychiatrists' decision-making might also have been affected by omission bias. Psychiatrists in the self role might focus predominantly on the unpleasantness of the more invasive treatment option (for example needle pain of depot) whereas they do not consider the risk of omitting an effective treatment for relapse prevention. Previous research has shown that omission bias might be more frequent in personal decision makers than in advice givers. ${ }^{11}$

Furthermore, the study revealed that doctors in the self role estimated the less invasive options to be more effective than doctors surveyed under the other conditions. This finding might be explained by dissonance theory, ${ }^{16}$ which states that after a decision, people tend to defend their decision in order to maintain consistency and to reduce cognitive dissonance. ${ }^{17}$ Thus, considering a less invasive treatment option as more effective may help doctors who chose this option to reduce cognitive dissonance. The same might hold true for the finding that psychiatrists in the self role perceived treatment guidelines as less important for their own treatment decision.

\section{Why did the question 'What would you do if you were me, doctor?' not motivate doctors to reveal their personal preferences?}

There might be several reasons why doctors do not share their preferences with their patients, even when being asked for them. 
First, this quasi 'private' question is being asked in the context of a professional patient-physician consultation, with clear roles and legal responsibilities. ${ }^{18,19}$ If psychiatrists reveal their personal preferences and a patient follows this recommendation (for example not to take drugs in the case of depression), the psychiatrists may - as discussed above - be held accountable for any negative consequences and possibly face legal challenge.

In addition, the question 'What would you do if you were me, doctor?' might itself be ambiguous. Do patients expect physicians to put themselves in the patient's situation, i.e. 'If you had my medical status along with my personal history and my values, what would you do?' Or do they expect physicians to reveal what they would do if they themselves were ill (i.e. with their own personal history and their own values - and with their own professional expertise)?

Finally, the question implies both seeing things as the patient experiences them and remaining oneself. ${ }^{2}$ However, being both oneself and the patient at the same time is mutually exclusive: 'How can one person - with his own biological wherewithal, experiences, history, frame of mind etc., assume the place of another person - with his or her own unique personal, bodily, social, and historical situation?' ${ }^{2}$ Answering the question 'What would you do if you were me, doctor?' might therefore be impossible. .,20 $^{2}$

\section{How can psychiatrists respond to the question 'What would you do if you were me, doctor?'}

Should they decline to answer the question and thus leave the patient to make the decision alone? Or, should they give a 'normal' recommendation? One option might be to figure out why the person is asking such a question and what his or her concerns are and then discuss them with the individual. The physician may offer a recommendation from his/her professional (not personal) perspective, while accounting for the patient's personal situation and values when possible. ${ }^{1,21}$ However, psychiatrists should emphasise that their recommendations cannot replace the patient's active involvement in decision-making since they know themselves best. ${ }^{22}$ Thus, the physician's professional perspective and the patient's personal perspective are brought together to identify the best treatment option for the individual.

\section{Limitations}

Our experimental design potentially threatens external validity. It might be possible that physicians act differently in real-life situations and, for example, choose more effective treatment options when they really have depression or schizophrenia themselves. However, the experimental design of our study, including case vignettes, enabled the investigation of the influence of different roles in decision-making without being confounded by other factors (for example patient or situation characteristics ${ }^{23}$ ). Another limitation is that each participant of our study only passed through one of three experimental conditions and therefore role differences within an individual are unknown. However, taking into consideration that the participants might be more inclined to respond consistently ${ }^{24}$ by choosing the same treatment option for all three roles, we selected a between-participants design that is used in most experiments investigating differences between personal decision makers and advice givers. ${ }^{13,14,25}$

\section{Implications}

The results of our study indicate that the question 'What would you do if you were me, doctor?' did not motivate psychiatrists to leave their professional recommendation role and to take a more personal perspective. Considering our results and given that physicians do not always make the optimal decisions for themselves, ${ }^{26,27}$ it is questionable whether motivating physicians to slip into the patient role would really lead to a better recommendation than one given by physicians in their professional role. Psychiatrists should try to find out why patients are asking this question and, together with that individual, identify the most appropriate treatment option.

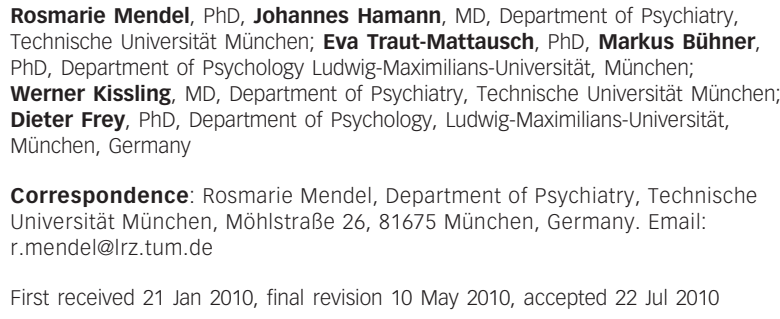

\section{Acknowledgements}

Grateful thanks to Rosa-Maria Conrad for the idea for this study and to all participating psychiatrists for their help.

\section{Appendix}

\section{Case vignettes}

\section{Depression scenario}

For regular recommendation role and what-would-you-do role. 'Imagine that for the past 3 weeks a patient of yours has been feeling increasingly sad and tired and is now seeking your advice for treatment. The patient finds it a struggle to go to work, which has become more and more stressful for months. Even hobbies no longer provide any pleasure.'

Self role. 'For the following experiment we would like you to imagine that for the past 3 weeks you have been feeling increasingly sad and tired. For this reason you are now seeking psychiatric treatment. You find it a struggle to go to work, which has become more and more stressful for months. Even your hobbies no longer provide any pleasure.'

\section{Schizophrenia scenario}

Regular recommendation role and what-would-you-do role. 'Imagine that you are treating a patient with schizophrenia who is currently experiencing a relapse. You are aware that the patient sometimes forgets to take the necessary antipsychotics.'

Self role. 'For the following experiment we would like you to imagine that you suffer from schizophrenia and are seeking psychiatric treatment. You are currently experiencing a relapse. Sometimes you forget to take the necessary antipsychotics.'

\section{References}

1 Baylis F, Downie J. Professional recommendations: disclosing facts and values. J Med Ethics 2001; 27: 20-4.

2 Zaner R. Physicians and patients in relation - clinical interpretation and dialogues of trust. In Handbook of Bioethics - Taking Stock of the Field from a Philosophical Perspective (ed G Khushf): 223-50. Kluwer Academic Publishers, 2004.

3 Hayes DF. What would you do if this were your ... wife, sister, mother, self? J Clin Oncol 1991; 9: 1-3. 
4 Gardner M, Ogden J. Do GPs practice what they preach? A questionnaire study of GPs' treatments for themselves and their patients. Patient Educ Couns 2005; 56: 112-5.

5 Steinert T. Which neuroleptic would psychiatrists take for themselves or their relatives? Eur Psychiatry 2003; 18: 40-1.

6 Belanger D, Moore M, Tannock I. How American oncologists treat breast cancer: an assessment of the influence of clinical trials. J Clin Oncol 1991; 9 ; $7-16$

7 Domenighetti G, Casabianca A, Gutzwiller F, Martinoli S. Revisiting the most informed consumer of surgical services. The physician-patient. Int J Techno Assess Health Care 1993; 9: 505-13.

8 Amering M, Denk E, Griengl H, Sibitz I, Stastny P. Psychiatric wills of mental health professionals: a survey of opinions regarding advance directives in psychiatry. Soc Psychiatry Psychiatr Epidemiol 1999; 34: 30-4.

9 Moncrieff J, Kirsch I. Efficacy of antidepressants in adults. BMJ 2005; 331 : $155-7$.

10 Raymark PH. Accepting or rejecting medical treatment: a comparison of decisions made for self versus those made for a significant other. $J$ Applied Soc Psychology 2000; 30: 2409-36.

11 Zikmund-Fisher BJ, Sarr B, Fagerlin A, Ubel PA. A matter of perspective: choosing for others differs from choosing for yourself in making treatment decisions. J Gen Intern Med 2006; 21: 618-22.

12 Jonas E, Schulz-Hardt S, Frey D. Giving advice or making decisions in someone else's place: the influence of impression, defense, and accuracy motivation on the search for new information. Pers Soc Psychol Bull 2005: 31: $977-90$.

13 Kray L, Gonzalez R. Differential weighting in choice versus advice: I'll do this, you do that. J Behav Decis Making 1999; 12: 207-17.

14 Kray L. Contingent weighting in self-other decision making. Organ Behav Hum Decis Process 2000; 83: 82-106.
15 Belcher VN, Fried TR, Agostini JV, Tinetti ME. Views of older adults on patient participation in medication-related decision making. J Gen Intern Med 2006; 21: 298-303.

16 Festinger L. A Theory of Cognitive Dissonance. Stanford University Press, 1957.

17 Frey D. Recent research on selective exposure to information. In Advances in Experimental Social Psychology, Vol 19 (ed L Berkowitz ): 41-80. Academic Press, 1986

18 Heimer CA. Responsibility in health care: spanning the boundary between law and medicine. Wake Forest Law Rev 2006; 41: 465-507.

19 Sharpe VA. Behind closed doors: accountability and responsibility in patient care. J Med Philos 2000; 25: 28-47.

20 Spiegelberg H. Steppingstones toward an Ethics for Fellow Existers. Essays 1944-1983. Martinus Nijhoff Publishers, 1986.

21 Ubel PA. "What should I do, doc?": some psychologic benefits of physician recommendations. Arch Intern Med 2002; 162: 977-80.

22 Quill TE, Brody H. Physician recommendations and patient autonomy: finding a balance between physician power and patient choice. Ann Intern Med 1996; 125: 763-9.

23 Jones TV, Gerrity MS, Earp J. Written case simulations: do they predict physicians' behavior? J Clin Epidemiol 1990; 43: 805-15.

24 Podsakoff PM, MacKenzie SB, Lee JY, Podsakoff NP. Common method biases in behavioral research: a critical review of the literature and recommended remedies. J Appl Psychol 2003; 88: 879-903.

25 Jonas E, Frey D. Information search and presentation in advisor-client interaction. Organ Behav Hum Decis Process 2003; 91: 154-68.

26 Chambers R, Belcher J. Self-reported health care over the past 10 years: a survey of general practitioners. Br J Gen Pract 1992; 42: 153-6.

27 Tyssen R. Health problems and the use of health services among physicians: a review article with particular emphasis on Norwegian studies. Ind Health 2007; 45: 599-610.

\section{Psychosis in the Firdaus al-Hikmat, the first major Arabic medical text}

\section{Neil Aggarwal}

Abū al-Hasan Ali ibn Sahl Rabban al-Tabari, known in the Islamic medical tradition as Rabban al-Tabari, wrote the first major Arabic medical text, Firdaus al-Hikmat ('The Paradise of Wisdom'), in the 9th century. He was descended from a learned family in Tabaristan, Iran and served three Abbasid caliphs as court physician. Fluent in Syriac and Greek, al-Tabari recorded his observations on the opinions of Western authorities such as Hippocrates and Galen as well as Indian experts like Sushruta and Charaka. Historical accounts verify that his text circulated widely.

The Paradise of Wisdom lays out diagnoses, symptoms and treatments based on organ systems similar to those in contemporary textbooks. Psychiatrists can recognise his interests in neuroanatomical localisation and descriptive psychopathology. Under the section 'On the signs of the diseases of the brain and what appears in them', al-Tabari has detailed the causes and manifestations of major diseases. Though we now consider fantasy, thought and memory to be complex operations of neural interconnections across many pathways, he attributed their locations to the front, middle and back of the brain respectively. Deficits in these areas from corruption of the humours elicited unique symptoms and resulted in the majority of psychiatric disturbances.

For al-Tabari, the entire brain housed the rational self. Global lesions produced what we understand as psychotic symptoms. He noted common delusions: some thought they were made of pottery and feared they would shatter upon touching objects; some thought the sky was falling and proceeded slowly while yelling; some thought they were wild camels and fled from people; some believed they were chickens and shouted accordingly. al-Tabari also noted the following hallucinations: hearing sounds and rings despite their absence, seeing fire or gadflies between the eyes, seeing doubly. His anecdotes illustrate a major theme within cultural psychiatry - the biology of people across societies remains conserved even as they draw upon different cultural meanings to express symptoms. 